Article

\title{
Impact of Orifice-to-Pipe Diameter Ratio on Leakage Flow: An Experimental Study
}

\author{
Tingchao Yu ${ }^{1}\left(\mathbb{D}\right.$, Xiangqiu Zhang $^{1}$, Iran E. Lima Neto ${ }^{2}$, Tuqiao Zhang ${ }^{1}$, Yu Shao ${ }^{1}(\mathbb{C}$ \\ and Miaomiao $\mathrm{Ye}^{1 \text {,* }}$ \\ 1 Department of Civil Engineering, Zhejiang University, Hangzhou 310058, China; \\ yutingchao@zju.edu.cn (T.Y.); zhangxiangqiu@zju.edu.cn (X.Z.); ztq@zju.edu.cn (T.Z.); \\ shaoyu1979@zju.edu.cn (Y.S.) \\ 2 Department of Hydraulic and Environmental Engineering, Federal University of Ceará, \\ Fortaleza 60451-970, Brazil; iran@deha.ufc.br \\ * Correspondence: yemiao008@zju.edu.cn
}

Received: 23 September 2019; Accepted: 18 October 2019; Published: 21 October 2019

\begin{abstract}
The traditional orifice discharge formula used to estimate the flow rate through a leak opening at a pipe wall often produces inaccurate results. This paper reports an original experimental study in which the influence of orifice-to-pipe diameter ratio on leakage flow rate was investigated for several internal/external flow conditions and orifice holes with different shapes. The results revealed that orifice-to-pipe diameter ratio (or pipe wall curvature) indeed influenced the leakage flow, with the discharge coefficient $\left(C_{d}\right)$ presenting a wide variation (0.60-0.85). As the orifice-to-pipe diameter ratio decreased, the values of $C_{d}$ systematically decreased from about $12 \%$ to $3 \%$. Overall, the values of $C_{d}$ also decreased with $\beta$ (ratio of pressure head differential at the orifice to wall thickness), as observed in previous studies. On the other hand, orifice shape, main pipe flow velocity, and external medium (water or air) all had a secondary effect on $C_{d}$. The results obtained in the present study not only demonstrated that orifice-to-pipe diameter ratio affects the outflow, but also that real scale pipes may exhibit a relevant deviation of $C_{d}$ from the classical range (0.61-0.67) reported in the literature.
\end{abstract}

Keywords: discharge; orifice; pipe leakage; orifice-to-pipe diameter ratio; water distribution system; discharge coefficient

\section{Introduction}

A water distribution system is an essential part of urban infrastructures, and its integrity and reliability play an important role in ensuring the rapid and stable development of a city's economy and the improvement of people's living standards [1]. Pipe network leakage in many countries frequently occurs in a distribution system when the inside pressure is higher than the outside pressure, and the pipes experience failures, including pipe fracture or orifice, cross connection, and leaking joints [2-5]. The amount of water leakage in pressurized pipes varies in different areas [3,6,7], which may seriously damage nearby infrastructures and cause third party damage, water and financial losses, energy losses, and health risks [8].

Orifice flow has been extensively studied, and the hydraulic behavior of the leaks is described by an orifice equation [9]. The famous Torricelli's formula, aiming at an orifice in the bottom of a tank with steady flow pattern and constant head, is generally used to estimate the discharge flow rate as follows:

$$
Q=C_{d} A \sqrt{2 g H},
$$


where $C_{d}=$ discharge coefficient, $g=$ acceleration of gravity, $A=$ orifice area, and $H=$ head in the tank. The conventional orifice equation, which describes the conversion of pressure energy to kinetic energy, is commonly used in leakage assessment.

Several studies have suggested that the areas of leak openings are not fixed when using the orifice equation, varying with the variation of fluid pressure caused by the stress changes in internal pipe walls. Fixed and variable area discharge theories have been used to describe the orifice flow [10-15]. Under elastic conditions, the area linearly changes with pressure, and the linear law is applicable regardless of the shape and size of the orifice, pipe material, and loading state of section properties [16]. Round holes slightly expand with pressure, and longitudinal cracks exhibit the largest increase, followed by circumferential cracks [15]. As a consequence, the leakage flow through a crack in a pipe cannot be accurately described by the conventional orifice equation.

To overcome this problem, leakage discharge is commonly modeled by using a power equation to describe the flow-pressure relationship in hydraulic network modeling [2,17-19]:

$$
Q=C h^{\alpha},
$$

where $C=$ leakage coefficient, $\alpha=$ leakage exponent, and $h=$ pressure differential in the orifice. Many studies have concluded that the leakage exponent varies with some factors, such as the type of pipe materials, size and shape of defects, and pipe diameters [2,20]. The power equation allows the leakage exponent to be higher than 0.5 , ranging from 0.5 to 2.79 with a median of 1.15 [21,22].

A comprehensive understanding of the relationship between leakage and various factors can help predict the leakage flow rate and reduce the losses in order to improve the reliability of a water supply network $[23,24]$. However, to the authors' knowledge, the only study dealing with the effect of pipe wall curvature on the flow rate through leak openings was performed by using a 2D computational fluid dynamics (CFD) model to estimate the intrusion rate into the pipelines [25].

The conventional orifice Equation (1) was derived from an orifice located at the tank wall on the basis of energy balance, where the tank wall is a plane. The wall of an actual pipe has a certain curvature. The divergent diameters of pipes essentially indicate that the plane located in the orifice is different. This study focused on the effect of orifice-to-pipe diameter ratio on leakage through pipe wall cracks. Various laboratory experiments were conducted, and the experimental systems were thoroughly described. The leakage discharge coefficient $\left(C_{d}\right)$ was measured under various orifice-to-pipe diameter ratio and pressure conditions. Two external media, namely, water and air, three different orifice shapes, and two sizes of orifices were also considered and compared. The key findings of this experimental study are summarized in the conclusions section.

\section{Experimental Study}

\subsection{Experimental Apparatus}

An experimental orifice discharge facility was built to measure the leakage volumes by simulating the leakage of pressurized underground pipe under two conditions, namely, water and air, external to the leakage opening of the pipe wall. Figure 1 shows the schematic of the experimental setup: a cuboid stainless steel water tank (2500 $\mathrm{mm}$ length, $600 \mathrm{~mm}$ width, $1000 \mathrm{~mm}$ height, and $4 \mathrm{~mm}$ wall thickness), with a straight round pipeline running through it. The pipe outside the tank was a DN50 straight pipeline, and the test pipe with various specifications inside was detachable and connected to the pipeline outside by Victaulic, with a total length of $18 \mathrm{~m}$. Twelve circular detachable pipes $(2000 \mathrm{~mm}$ length, $2 \mathrm{~mm}$ wall thickness) were located in the pipe section of the tank, in which four of them had $25 \mathrm{~mm}$ nominal diameter, the other four had $50 \mathrm{~mm}$ nominal diameter, and the remaining pipes had $100 \mathrm{~mm}$ nominal diameter, imitating a series of buried pipelines with different sizes in the experiment.

As shown in Figure 2, the leakage openings with different sizes and shapes were drilled at high precision in the middle length of the replaceable tubes for the simulation inside the tank: a round hole ( 3 and $6 \mathrm{~mm}$ in diameter), a longitudinal break ( $7.07 \mathrm{~mm}$ length, $1 \mathrm{~mm}$ width), and a circumferential 
split with the same measure in the middle of the detachable pipe wall. The physical model had a noncirculating system. The water tank on high experimental platform was used as water supply source to ensure the continuous flow of water, and the downstream overflow tank was used to drain water. Various pressures and velocities of the internal pipe during steady-state discharge were imposed as suitable experimental conditions using gate valves installed on the pipe, a variable-speed pump (50AAB HLS-25-50-2, Shanghai Panda, $5.5 \mathrm{~kW}$ rated power, and 0.5 MPa), and a diaphragm pressure tank (SQL600-0.6, Shanghai Panda, 0.6 MPa pressure, 120 L effective volume) in the experimental platform.

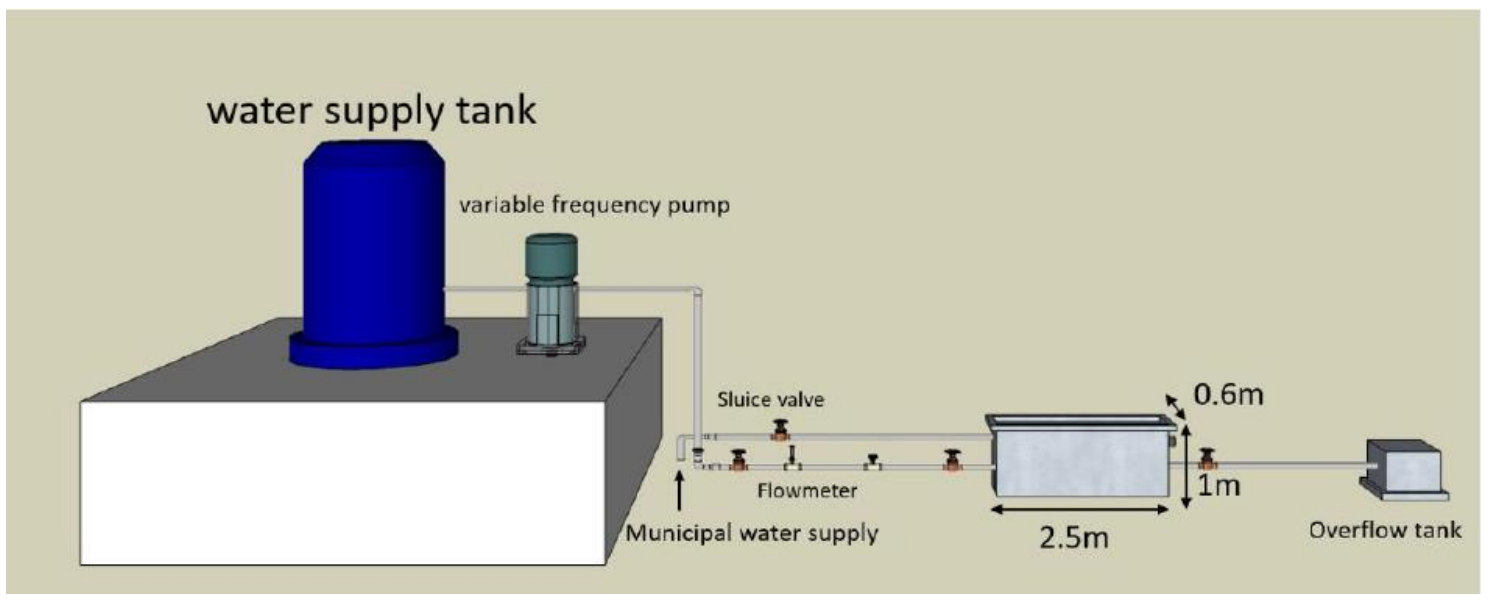

Figure 1. Schematic of the experimental setup for the outflow discharge study.

An electromagnetic flowmeter (OPTIFLUX2100C, KROHNE, Shanghai, China) with 5\% accuracy was installed on the upstream pipe section of the orifice to measure the pipe flow rate. Two Pi605CS pressure sensors (IP 68, with a range of 5 bar and 5\% accuracy, Manufacturer: Berkshire, England, Supplier: Shenzhen, China) connected to a data acquisition card were installed on the pipe positions to collect the pressure at the orifice, which upstream and downstream of the orifice and $0.3 \mathrm{~m}$ from the orifice of each pipe. The average reading of two pressure sensors was regarded as the orifice pressure. The pressure and flow data in the physical model were captured on LabVIEW software. The range of pressure transmitter was 5 bar and had a precision of $0.1 \%$, and the average of collected data was taken as the orifice pressure. Figure 3 illustrates the different parts of the experimental equipment for discharge flow simulation.

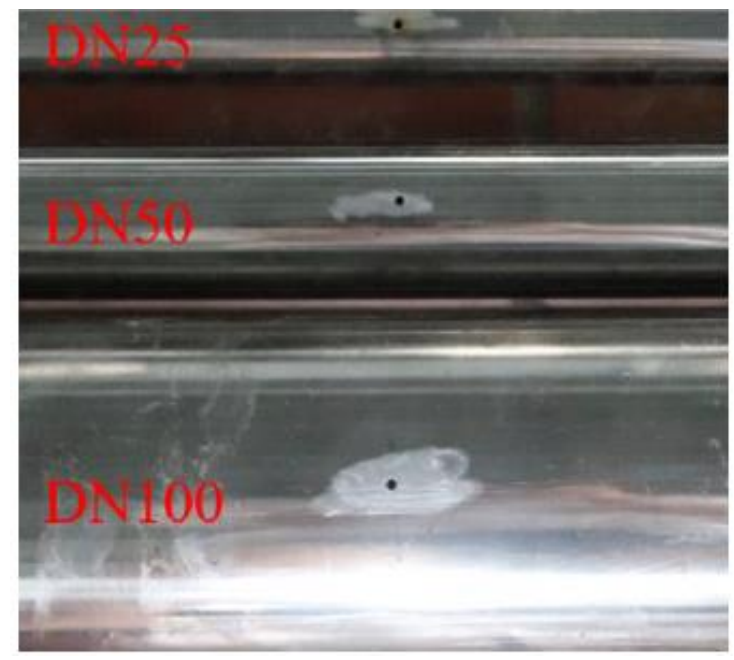

(a)

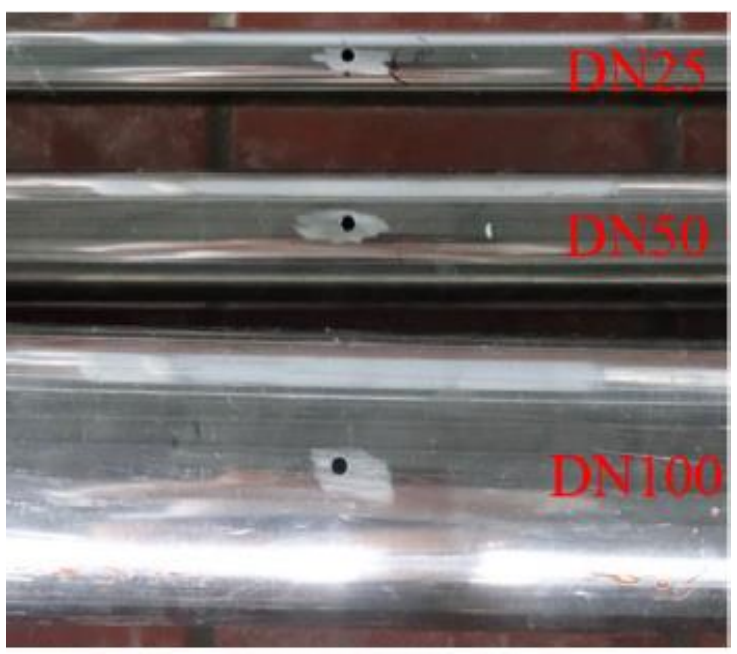

(b)

Figure 2. Cont. 


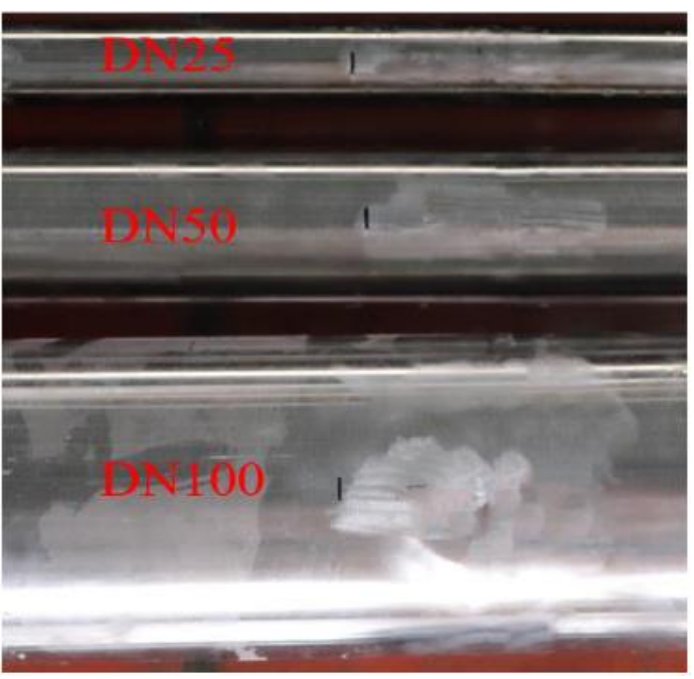

(c)

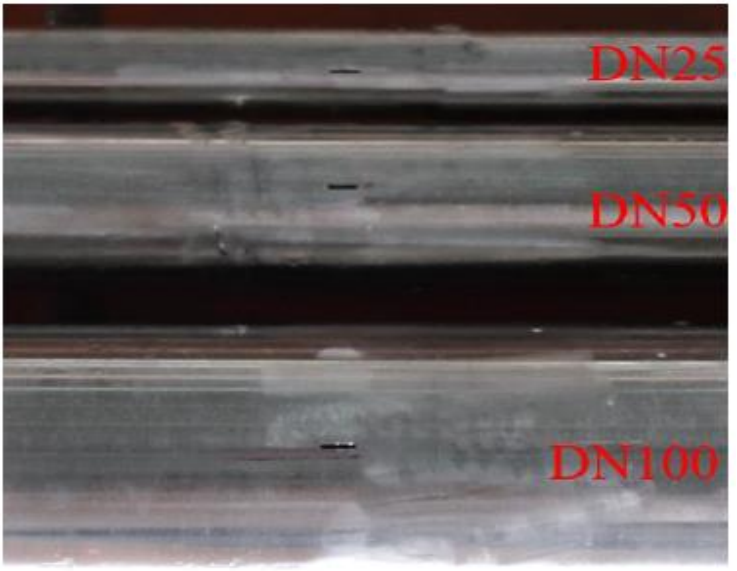

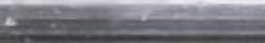

(d)

Figure 2. Photos of leakage openings with different areas and shapes in pipes with different diameters: (a) $3 \mathrm{~mm}$ circular orifice, (b) $6 \mathrm{~mm}$ circular orifice, (c) longitudinal orifice $(7 \mathrm{~mm}$ length and $1 \mathrm{~mm}$ width), and (d) circumferential orifice (7 mm length and $1 \mathrm{~mm}$ width).
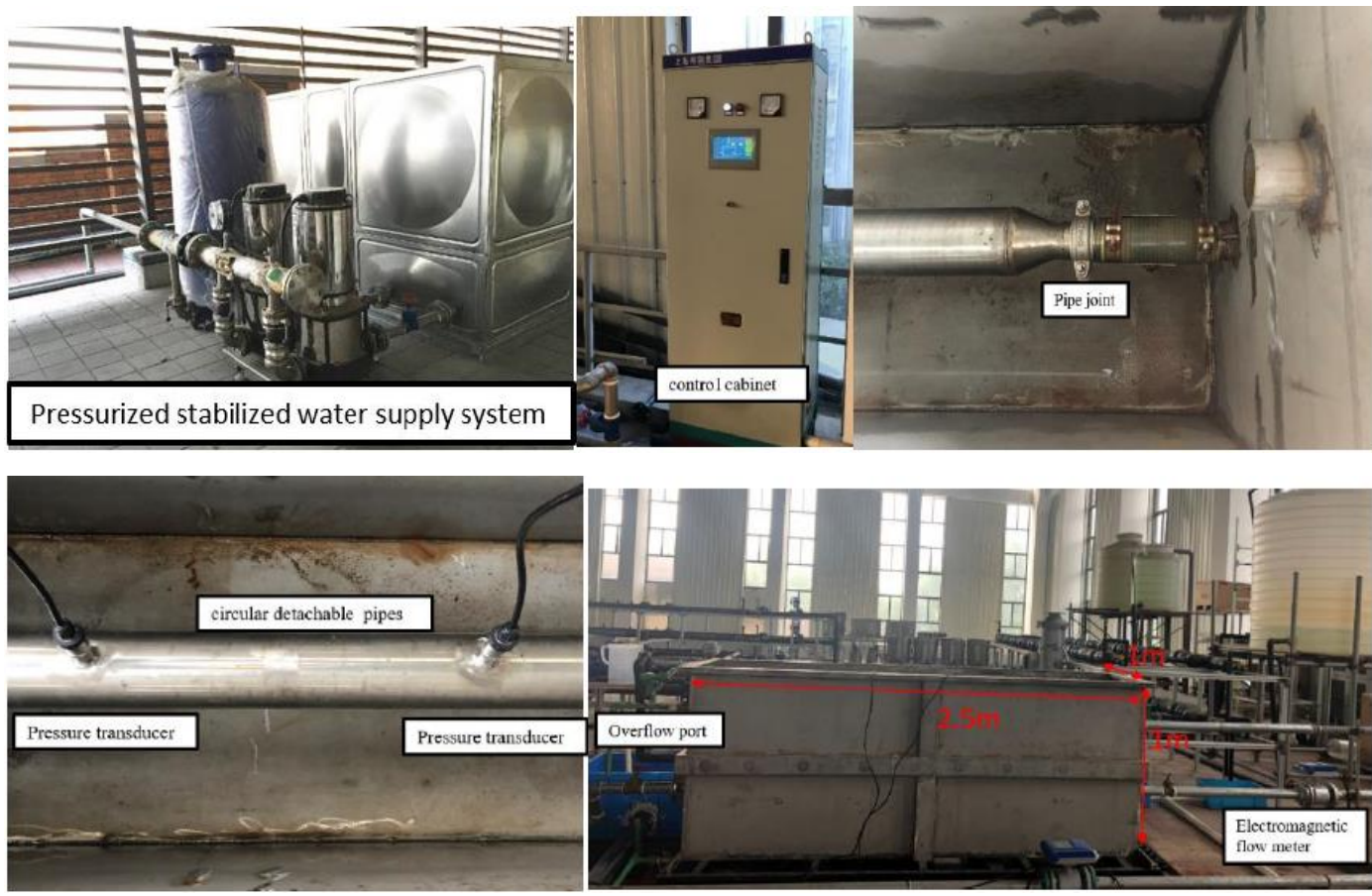

Figure 3. Experimental apparatus to control system operation.

\subsection{Experimental Procedures}

The pump started at different frequencies to perform the experiments with various scenarios, and the diaphragm valve upstream and downstream changed the switching degree to obtain various internal pressures and pipe flow rates. After acquiring the pressure and flow velocity data in each scenario on LabVIEW software, the entire experimental system ran for a time period under steady-state conditions to guarantee the accuracy of the measured outflow rate. The leakage flow rate in the pipe was measured through mass weighting (the ratio of water net weight at this time period was taken as the flow rate of leakage port). Various experiments were conducted considering air and water around the pipe, with water received under the orifice and at the overflow on the side of the tank 
(exactly $0.5 \mathrm{~m}$ above the orifice). The flow rate was measured by weighing the leakage flow under the orifice when conducting experiments of the orifice discharging into air. The side wall of the box was drilled with an overflow hole (100 $\mathrm{mm}$ diameter), and the size of the overflow nozzle was sufficient to discharge the water leakage in time when conducting the leakage opening into water, and the water flow in the overflow orifice was equal to the leakage amount in the orifice of the pipe when conducting experiments with water around the pipe. Each scenario was repeated at least five times to improve the accuracy of the results and reduce the errors, and the average of the data from the repeated experiments was set as the final data.

\subsection{Experimental Results}

The leakage discharge coefficient of the crack is calculated by using Equation (3):

$$
C_{d}=\frac{Q}{A \sqrt{2 g \Delta H}}
$$

where $Q$ is the leakage flow, $A$ is the orifice area, and $\Delta H$ is the pressure head differential over the crack in the pipe wall, $\left(h_{\text {internal }}-h_{\text {external }}\right)$. This study presented the discharge coefficient from the physical model obtained for different orifice shapes and different areas of circular holes under various experimental scenarios. In this study, the dimensionless parameter $\lambda$-the orifice-to-pipe diameter ratio-was introduced to extract the correlations more clearly between coefficient of discharge $\left(C_{d}\right)$ and the two factors (pipe diameter, orifice diameter). Different wall thicknesses bear the pressure differential between inside and outside a pipe in different ranges in actual conditions and pressure differential of unit wall thickness could reflect the influence of different pipeline material. Also, this study introduced the nondimensional parameter $\beta$ (ratio of pressure head differential at the orifice to wall thickness) and studied its impact on orifice leakage. As mentioned above, the experiments with the same system were divided into two parts, considering either air medium or water around the pipe to simulate groundwater environment.

\subsubsection{Discharge Coefficient for the Experiments with Water as External Medium}

In this experimental scenario, the main pipe flow velocity was kept approximately the same while the other flow conditions changed from one experiment to another. Note that the impact of flow velocity on discharge flow has already been investigated [26]. Figure 4 shows the results of discharge coefficient with 3 and $6 \mathrm{~mm}$ drilled orifices discharging into water with the variation of nondimensional parameter $\beta$ and the pipe filled and submerged in the water. The leakage flow rate in the existing leak openings and the discharge coefficient decreased with the increase of $\beta$. This condition conformed to the fitted curve formulas of International Organization for Standardization, manifesting that coefficient of discharge $\left(C_{d}\right)$ was closely related to the Reynolds number [18]. The difference in pressure head differential at the orifice caused the variation of $\beta$ due to the same wall thickness $(2 \mathrm{~mm})$ in the experiment. Regardless of pipe diameter and the orifice discharging into water below $10 \mathrm{~m}$ ( $\beta=5000)$ and above $40 \mathrm{~m}(\beta=20,000), C_{d}$ had a small fluctuation, and a conclusion was not made about $C_{d}$ and $\beta$ [27]. In relatively low-pressure zones, the cross-sectional area at the vena contraction is large (close to the orifice area) and changes little with pressure head differential, resulting in little variation in the contraction coefficient. Similarly, the contraction coefficient has the same trend under high-pressure zones. The contraction coefficient as a main factor affected $C_{d}$ and $C_{d}$ then seemed to be constant below $10 \mathrm{~m}$ and above $40 \mathrm{~m}$. In other words, $C_{d}$ decreased with the increase of pressure under intermediate pressure [27].

The discharge coefficient deviation under different pipe sizes and relatively low-pressure zone was larger than that under high-pressure zone. This suggests that the discharge coefficient had high sensitivity to the curvature degree of the pipe wall where the orifice was located under low pressure. The pressure potential energy plays a leading role under high pressure, with other factors having little 
impact on leakage flow rate. Comparing the values of charts (a) and (b) in Figure 4, we found that the value of $C_{d}$ in the $3 \mathrm{~mm}$ orifice with the same pressure and main pipe flow velocity was smaller than that in the $6 \mathrm{~mm}$ orifice because of the pipe losses in addition to the inlet and outlet losses of the small orifice, which is consistent with the results of $C_{d}$ by previous studies [28]. This means that $C_{d}$ decreased when $\lambda$ decreased under the same pipe diameter. The experimental results also indicated that $C_{d}$ decreased when $\lambda$ decreased under the same orifice diameter.

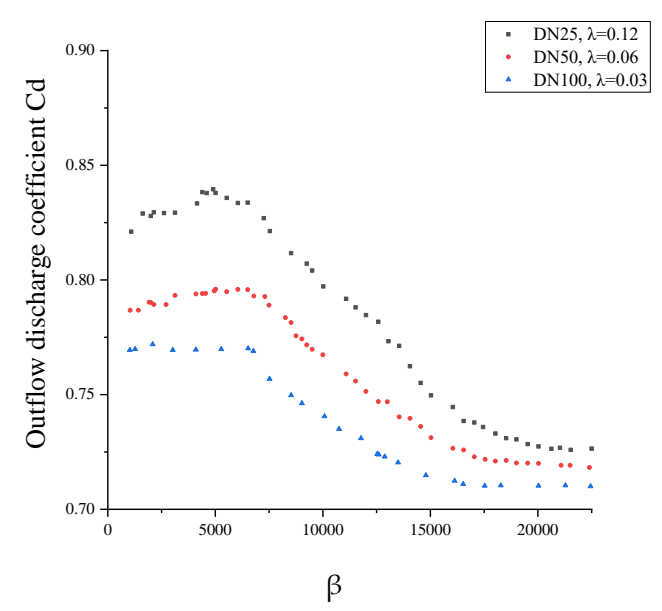

(a)

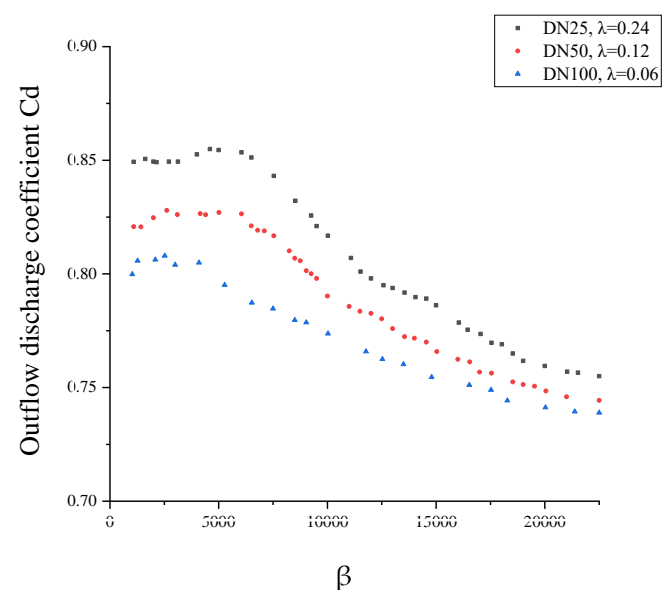

(b)

Figure 4. Variation of outflow discharge coefficient of round orifices discharging into water as a function of $\alpha$ and pipe diameter: (a) $3 \mathrm{~mm}$ orifice; (b) $6 \mathrm{~mm}$ orifice.

\subsubsection{Discharge Coefficient for the Experiments with Air as External Medium}

Similar to the abovementioned experiments, the main pipe flow velocity was kept approximately the same while the other flow conditions changed from one experiment to another. Figures 5 and 6 show the variation of $C_{d}$ with orifices of different sizes and shapes discharging into air as a function of $\beta$. The results indicate that the discharge coefficient decreased with the increase of pipe diameter regardless of the orifice size and shape. Comparing Figures 4 and 5 , we can observe that $C_{d}$ is larger for the orifice discharging into water than into air. However, the drop in $C_{d}$ values is more pronounced in the case of water. Additionally, in both figures, with the same orifice, $C_{d}$ decreased as $\lambda$ decreased. On the other hand, Figure 6 shows that the values of $C_{d}$ for the longitudinal crack were larger than those for the circumferential crack. The longitudinal cracks show larger expansion with pressure and also produce more leakage, followed by the circumferential crack $[2,15]$. This confirms that leakage water flow rate depends on the crack shape under the same flow conditions [2].

The equivalent diameter of the crack is calculated by using Equation (4) [29]:

$$
d_{e q}=1.55 \frac{A^{0.625}}{P_{w}^{0.25}}
$$

where $d_{e q}$ is the equivalent diameter, $A$ is the orifice area, and $P_{w}$ is the wetted perimeter of the orifice. Equation (4) was used to relate cracks with different shapes to the round holes and then calculate the orifice-to-pipe diameter ratio. The results also indicate that $C_{d}$ for the orifice discharging into water is higher than the typical values found in the literature, which are commonly between 0.61 and 0.67 for a circular sharp-edged leakage opening [30], and also higher than the value of $C_{d}$ for the case of air as external medium, consistent with previous experimental results [26,27]. 


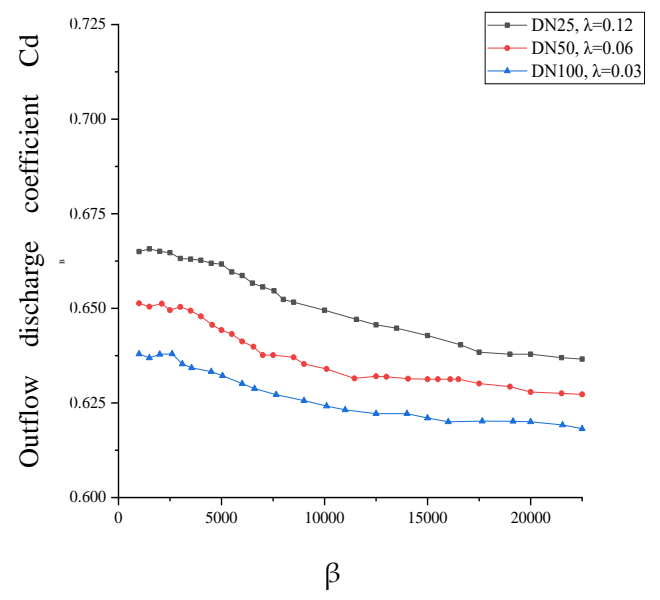

(a)

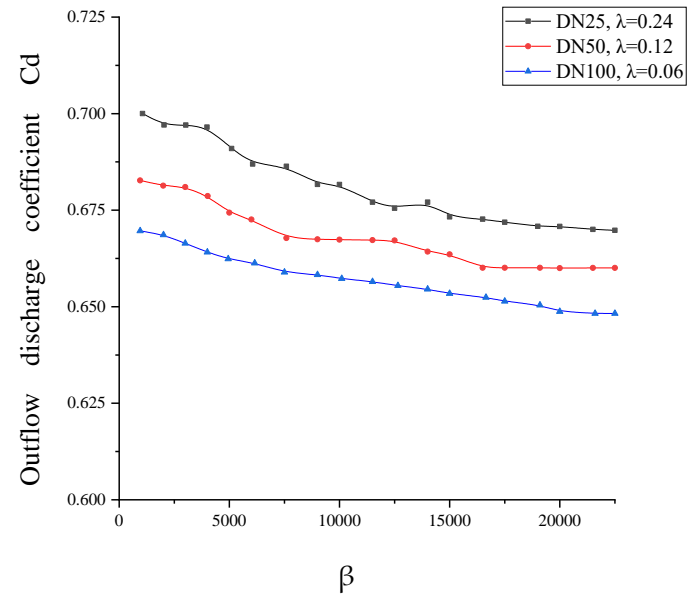

(b)

Figure 5. Variation of outflow discharge coefficient of round orifices discharging into air as a function of leakage pressure and pipe diameter: (a) $3 \mathrm{~mm}$ orifice; (b) $6 \mathrm{~mm}$ orifice.

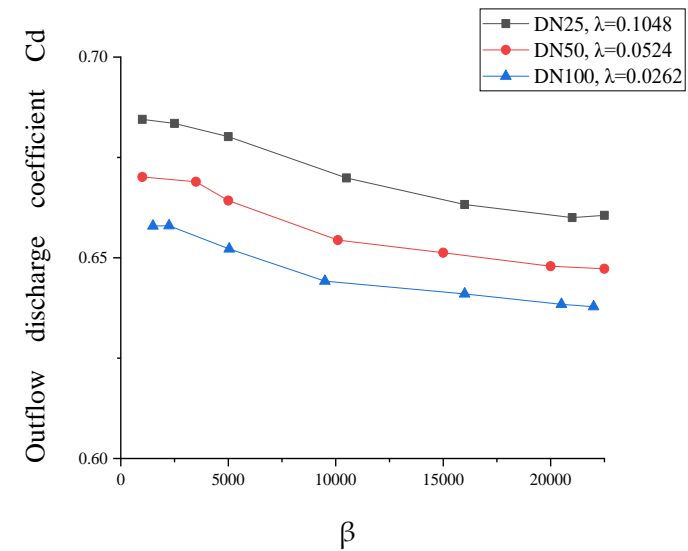

(a)

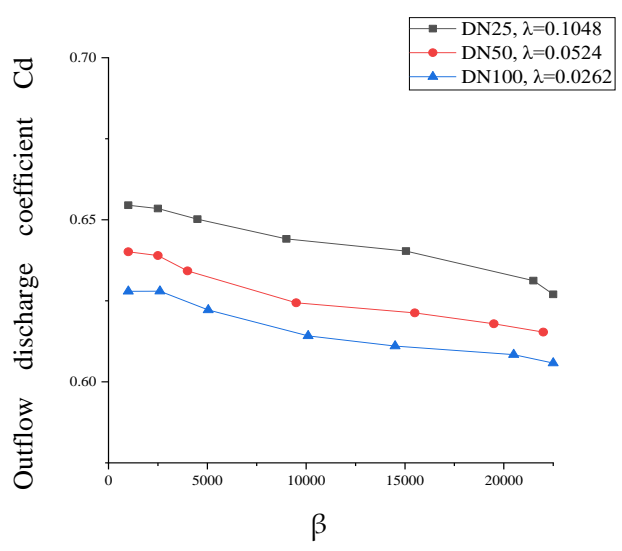

(b)

Figure 6. Variation of outflow discharge coefficient of orifices with different shapes discharging into air as a function of $\alpha$ and pipe diameter: (a) longitudinal crack; (b) circumferential crack.

\subsubsection{Effect of Reynolds Number}

The outflow experiments were conducted using the $3 \mathrm{~mm}$ orifice with three pipe diameters $(25,50$, and $100 \mathrm{~mm})$ discharging into air, as shown in Figure 7 . The pipe pressure was controlled at $10 \mathrm{~m}$, and the main pipe velocity was changed to a certain range using the same test system. Reynolds numbers were accurately calculated for each main pipe velocity. As demonstrated in Figure 7, the relationship of $C_{d}$ and Reynolds number was indicated, and the discharge coefficient curves with different value of Reynolds number were obtained. Regardless of the flow velocity within the testing range (below $1 \mathrm{~m} / \mathrm{s}$ ), the larger Reynolds number is, the smaller the $C_{d}$ will be, consistent with the results available in the literature [26]. When $\lambda$ is constant, the larger Reynolds number leads to greater influence of inertial force, more water flowing downstream of the pipe section and less leakage at the orifice. Among the three different values of $\lambda$ with the same orifice diameter, the curve slope related to $\lambda$ with maximum value was the largest. However, the drop in $C_{d}$ was very small for all the cases $(<2 \%)$, which suggests that the discharge coefficient was not strongly influenced by Reynolds number. 


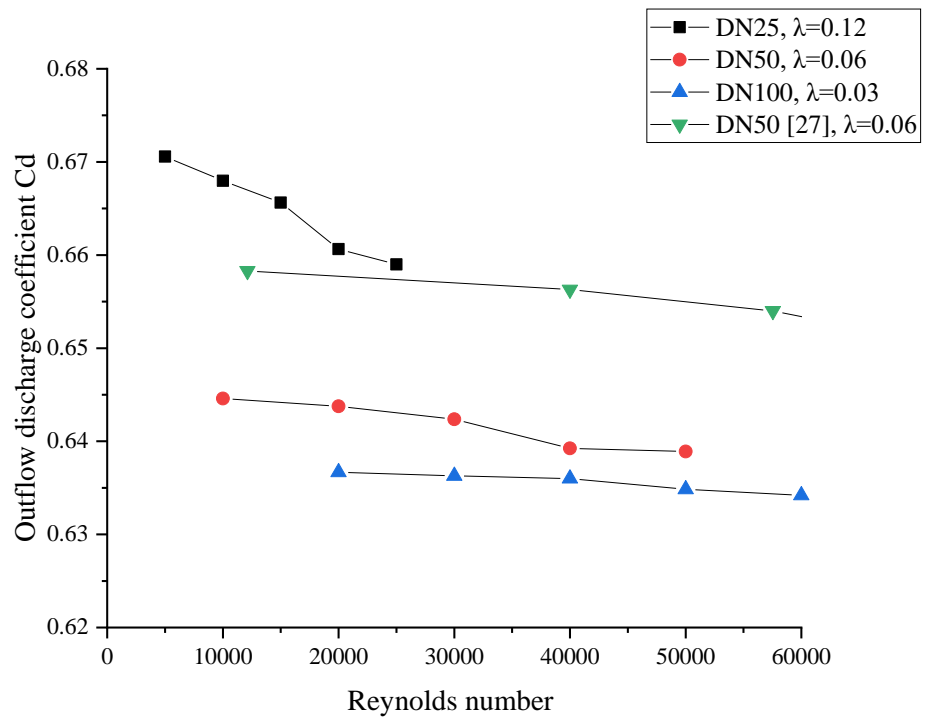

Figure 7. Variation of outflow discharge coefficient for the $3 \mathrm{~mm}$ circular hole discharging into air as a function of Reynolds number.

\subsubsection{Synthesis of the Experimental Results}

Overall, Figures $4-7$ show that decreasing $\lambda$ (from 0.12 to 0.03 , and from 0.24 to 0.06 ) results in systematic decreases of $C_{d}$ from about $12 \%$ to $3 \%$, independently of the external medium (air or water), orifice size and shape, and main pipe flow velocity, which played a secondary role on $C_{d}$. On the other hand, $C_{d}$ also decreased with the pressure head differential at the orifice, corroborating earlier experimental results [27].

The decrease of $C_{d}$ with pipe diameter is attributed here to the effect of pipe wall curvature on the convergent flow towards the orifice. Comparing our results with those obtained in previous studies [26], we can conclude that $C_{d}$ gradually decreases from (a) to (c) in Figure 8, which represent, respectively, three flow conditions: outflow in a pipe with small diameter (with angle $\theta>0$ ), outflow in a pipe with large diameter (or a rectangular pipe, where $\theta=0$ ), and inflow to a pipe of small diameter (with angle $\theta>0$ ). Future studies are needed to elucidate these flow behaviors.

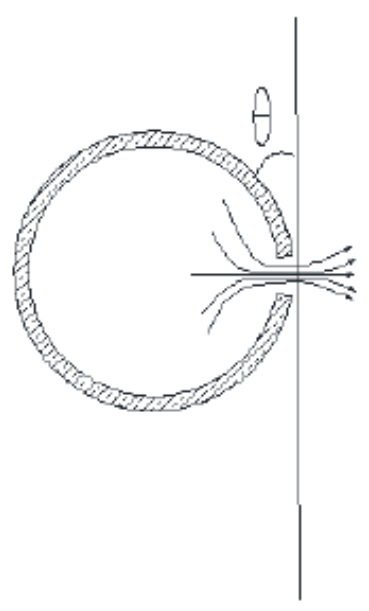

(a)

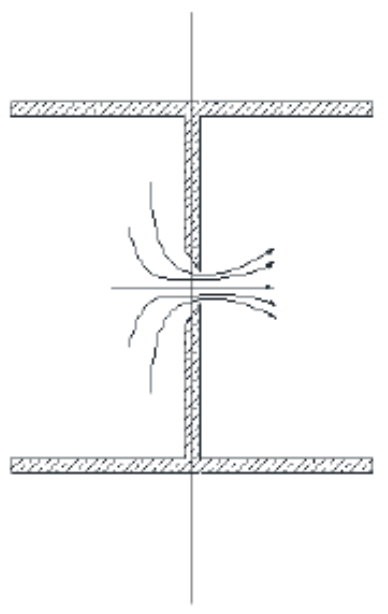

(b)

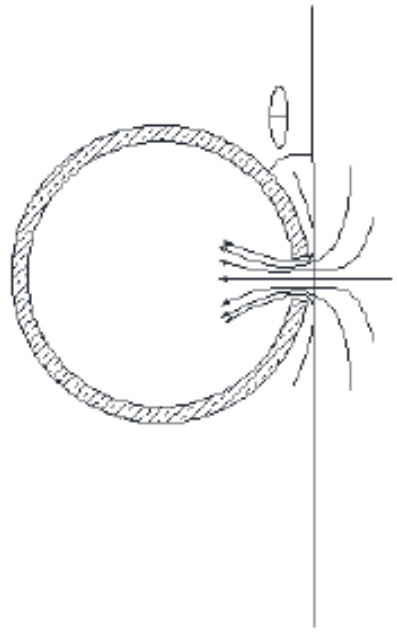

(c)

Figure 8. Leakage conditions with different pipe wall curvatures (and angle $\theta$ ): (a) outflow in a pipe with small diameter (with angle $\theta>0$ ); (b) outflow in a pipe with large diameter (or a rectangular pipe, where $\theta=0$ ); (c) inflow to a pipe of small diameter (with angle $\theta>0$ ) 


\section{Conclusions}

This study conducted various experiments to investigate the influence of the dimensionless parameter $\lambda$ (the orifice-to-pipe diameter radio) in water supply networks on orifice outflow. In particular, this study experimentally modeled the orifice outflow of pipes surrounded by water and air. The steady-state results from the physical modeling suggested that the dimensionless parameter $\lambda$ had a clear effect on the discharge coefficient using the orifice equation. The aim was to assess the relationship between $\lambda$ and outflow. Thus, the following conclusions can be drawn:

1. The dimensionless parameter $\lambda$ (the orifice-to-pipe diameter radio) indeed affected the pipe leakage with the same size of orifice. With constant orifice pressure and main pipe flow velocity, $\lambda$ increased (i.e., with the decrease of the pipe diameter, with the increase of pipe wall curvature), and the outflow discharge coefficient increased. The conclusion in the experimental results was true under three molds of opening leakage, namely, round hole, longitudinal crack, and circumferential crack. $C_{d}$ was more sensitive to $\lambda$ when the pipe was around the water under low pressure.

2. The discharge coefficient slightly increased with orifice diameter ( 3 and $6 \mathrm{~mm}$ ), which also suggests that a general relationship between $C_{d}$ and the dimensionless parameter $\lambda$ (the orifice-to-pipe diameter ratio) may exist. Further experimental and numerical studies will be carried out to investigate this potential relationship.

3. The water around the orifice favored the outflow. With similar main pipe velocity and constant orifice pressure, the value of $C_{d}$ in the orifice discharging into water was larger than that outflowing into air. $C_{d}$ also dropped faster with pressure in the case of air.

4. The experiments provided values of $C_{d}$ ranging from about 0.60 to 0.85 , which presented some deviations from the classical range of $0.61-0.67$ reported in the literature. This may have a relevant impact on real pipeline systems.

Author Contributions: Conceptualization, T.Y.; Methodology, T.Y. and X.Z.; Validation, M.Y.; Formal analysis, Y.S.; Writing-original draft preparation, T.Y. and X.Z.; writing-review and editing, I.E.L.N. and M.Y.; Visualization M.Y.; Supervision, T.Z.

Funding: The authors gratefully acknowledge the financial support from National Science and Technology Major Projects for Water Pollution Control and Treatment (No. 2017ZX07201003), International Cooperation and Exchange of the National Natural Science Foundation of China (No. 51761145022) and the Brazilian National Council for Scientific and Technological Development (No. 441115/2016-0).

Acknowledgments: The authors greatly thank Yanwei Cai and Yu Li for her help in the process of doing the experiments.

Conflicts of Interest: The authors declare no conflict of interest.

\section{References}

1. Kabir, G.; Tesfamariam, S.; Francisque, A.; Sadiq, R. Evaluating risk of water mains failure using a Bayesian belief network model. Eur. J. Oper. Res. 2015, 240, 220-234. [CrossRef]

2. Mora-Rodriguez, J.; Delgado-Galvan, X.; Ramos, H.M.; Lopez-Jimenez, P.A. An overview of leaks and intrusion for different pipe materials and failures. Urban Water J. 2014, 11, 1-10. [CrossRef]

3. Mamlook, R.; Al-Jayyous, O. Fuzzy sets analysis for leak detection in infrastructure systems: A proposed methodology. Clean Technol. Environ. Policy 2003, 6, 26-31. [CrossRef]

4. Fleming, K.; Dugandzic, J.; Lechevallier, M. Susceptibility of Distribution Systems to Negative Pressure Transients; American Water Works Research Foundation: Denver, CO, USA, 2007.

5. Besner, M.C.; Ebacher, G.; Lavoie, J. Low and negative pressures in distribution systems: Do they actually result in intrusion? In Proceedings of the World Environmental \& Water Resources Congress, Tampa, FL, USA, 15-19 May 2007.

6. Beuken, R.H.S.; Lavooij, C.S.W.; Bosch, A.; Schaap, P.G. Low leakage in the Netherlands confirmed. In Proceedings of the 8th Annual Water Distribution Systems Analysis Symposium, Cincinnati, OH, USA, 27-30 August 2006.

7. Lambert, A.O. Water losses management and techniques. Water Sci. Technol. Water Supply 2002, 2, 1-20. [CrossRef] 
8. Puust, R.; Kapelan, Z.; Savic, D.A.; Koppel, T. A review of methods for leakage management in pipe networks. Urban Water J. 2010, 7, 25-45. [CrossRef]

9. Van Zyl, J.E.; Lambert, A.O.; Collins, R. Realistic modeling of leakage and intrusion flows through leak openings in pipes. J. Hydraul. Eng. 2017, 143. [CrossRef]

10. May, J.H. Pressure dependent leakage. World Water Environ. Eng. 1994, 17, 10.

11. Ferrante, M.; Massari, C.; Brunone, B.; Meniconi, S. Experimental evidence of hysteresis in the head-discharge relationship for a leak in a polyethylene pipe. J. Hydraul. Eng. 2011, 137, 775-780. [CrossRef]

12. Massari, C.; Ferrante, M.; Brunone, B.; Meniconi, S. Is the leak head-discharge relationship in polyethylene pipes a bijective function? J. Hydraul. Res. 2012, 50, 409-417. [CrossRef]

13. Greyvenstein, B.; van Zyl, J.E. An experimental investigation into the pressure-leakage relationship of some failed water pipes. J. Water Supply Res. Technol. AQUA 2007, 56, 117-124. [CrossRef]

14. De Marchis, M.; Fontanazza, C.M.; Freni, G.; Notaro, V.; Puleo, V. Experimental evidence of leaks in elastic pipes. Water Resour. Manag. 2016, 30, 2005-2019. [CrossRef]

15. Cassa, A.M.; van Zyl, J.E.; Laubscher, R.F. A numerical investigation into the effect of pressure on holes and cracks in water supply pipes. Urban Water J. 2010, 7, 109-120. [CrossRef]

16. Malde, R. An Analysis of Leakage Parameters of Individual Leaks on a Pressure Pipeline through the Development and Application of a Standard Procedure. Master's Thesis, University of Cape Town, Cape Town, South Africa, 18 May 2015.

17. Van Zyl, J.E.; Cassa, A.M. Modeling elastically deforming leaks in water distribution pipes. J. Hydraul. Eng. 2014, 140, 182-189. [CrossRef]

18. Lambert, A. What do we know about pressure-leakage relationships in distribution systems. In Proceedings of the IWA Conference System Approach to Leakage Control and Water Distribution Systems Management, Brno, Czech Republic, 16-18 May 2000.

19. Giustolisi, O.; Savic, D.A.; Kapelan, Z. Pressure-driven demand and leakage simulation for water distribution networks. J. Hydraul. Eng. 2008, 134, 626-635. [CrossRef]

20. Salinas-Vázquez, M.; Vicente, W.; Carrizosa, E.; Osnaya, J.; Ballesteros, O. Estudio numérico y experimental de fugas en tubos elásticos. In Proceedings of the XXII Congreso Latinoamericano de Hidráulica, Guayana, Venezuela, 9 October 2006.

21. Farley, M.; Trow, S. Losses in Water Distribution Networks; IWA Publishing: London, UK, 2003.

22. López, P.A.; Fuertes, V.; Iglesias, P.; Martínez, J. Modelación mediante cfd de fugas en tuberías de redes de abastecimiento. In Proceedings of the V Seminario Iberoamericano de Planificación, Proyecto y Operación de Sistemas de Abastecimiento de Agua, Valencia, Spain, 29 November-2 December 2005.

23. Ashton, C.H.; Hope, V.S. Environmental valuation and the economic level of leakage. Urban Water J. 2001, 3, 261-270. [CrossRef]

24. Walski, T.; Bezts, W.; Posluszny, E.T.; Weir, M.; Whitman, B.E. Modeling leakage reduction through pressure control. J. Am. Water Work. Assoc. 2006, 98, 147-155. [CrossRef]

25. Mansour-Rezaei, S.; Naser, G. Contaminant intrusion in water distribution system: An ingress model. J. Am. Water Works Assoc. 2013, 105, E29-E39. [CrossRef]

26. Shao, Y.; Yao, T.; Gong, J.Z.; Liu, J.J.; Zhang, T.Q.; Yu, T.C. Impact of main pipe flow velocity on leakage and intrusion flow: An experimental study. Water 2019, 11, 118. [CrossRef]

27. Coetzer, A.; van Zyl, J.; Clayton, C. An experimental investigation into the turbulent-flow hydraulics of small circular holes in plastic pipes. In Proceedings of the 8th Annual Water Distribution Systems Analysis Symposium (WDSA), Cincinnati, OH, USA, 27-30 August 2006.

28. Collins, R.; Boxall, J. Influence of ground conditions on intrusion flows through apertures in distribution pipes. J. Hydraul. Eng. 2013, 139, 1052-1061. [CrossRef]

29. Mora-Rodríguez, J.; Delgado-Galván, X.; Ortiz-Medel, J. Pathogen intrusion flows in water distribution systems: According to orifice equations. J. Water Supply: Res. Technol. AQUA 2015, 64, 857-869. [CrossRef]

30. King, H.W.; Barter, E.F. Handbook of Hydraulics; McGraw-Hill: New York, NY, USA, 1976.

(C) 2019 by the authors. Licensee MDPI, Basel, Switzerland. This article is an open access article distributed under the terms and conditions of the Creative Commons Attribution (CC BY) license (http://creativecommons.org/licenses/by/4.0/). 